\title{
SOLARIZAÇÃO DE ÁGUA CONTAMINADA POR LEVEDURAS: SACCHAROMYCES CEREVISIAE E CANDIDA ALBICANS
}

\author{
A.A. Navarrete ${ }^{1}$, D.F. de Angelis ${ }^{1}$, A.C.S. Pião ${ }^{2}$
}

${ }^{1}$ Universidade Estadual Paulista, Instituto de Biociências, Departamento de Bioquímica e Microbiologia, Av. 24-A, 1515, CEP 13506-900, Rio Claro, SP, Brasil. E-mail: navarret@esalq.usp.br

\section{RESUMO}

\begin{abstract}
A fim de analisar a viabilidade celular de Saccharomyces cerevisiae e Candida albicans mantidas em suspensão aquosa acondicionada em frascos de vidro e garrafas de politereftalato de etileno - PET - incolores e verdes expostas à radiação solar direta, utilizaram-se células das leveduras para contaminar água de abastecimento público após neutralização do cloro por ação do tiossulfato de sódio. A suspensão celular resultante da contaminação foi distribuída nos diferentes tipos de frascos, os quais foram colocados sobre folhas de alumínio que revestiam bandejas utilizadas como suporte de modo a receberem máxima incidência luminosa. Nos intervalos temporais de $0,8,24$, $28,32,48,56,72$ e 76 horas (computando o período noturno) foram retiradas alíquotas e a viabilidade celular quantificada em câmara de Neubauer. Os resultados indicaram a eficiência da solarização da água para a eliminação celular de $S$. cerevisiae e $C$. albicans presentes em suspensão aquosa e evidenciaram que a exposição à radiação solar da água de consumo humano, acondicionada em frascos de vidro e garrafas PET, pode ser utilizada para diminuir o risco de enfermidades de veiculação hídrica.
\end{abstract}

PALAVRAS-CHAVE: Saccharomyces cerevisiae, Candida albicans, solarização, água, desinfecção.

\section{ABSTRACT}

SOLARIZATIONOFCONTAMINATEDWATER BYYEASTS:SACCHAROMYCESCEREVISIAE AND CANDIDA ALBICANS. This study the analyzed the cellular feasibility of Saccharomyces cerevisiae and Candida albicans in water suspension packed in glass flasks and in colorless (clear) and green bottles made of polyethylene terephthalate-PET - exposed to direct solar radiation, and with yeast cells added to the water obtained from the public supply system after neutralization of chlorine by sodium thiosulfate. The resulting cellular suspension was distributed in the different kinds of receptacles, which were placed on support trays covered with aluminum foil to increase theincidence of light. At the time intervals of $0 ; 8 ; 24 ; 28 ; 32 ; 48 ; 56 ; 72$ and 76 hours (counting the night period) samples were taken and the cellular feasibility was calculated in a Neubauer chamber. Results showed that direct sun radiation was effective for the cellular elimination of S. cerevisiae and C.albicans present in the water suspension. Results also showed that exposure of water placed in flasks of glass and in colorless (clear) and green bottles made of polyethylene terephthalate for human consumption can be used to diminish water-transmitted disease risks.

KEY WORDS: Saccharomyces cerevisiae, Candida albicans, solarization, water, disinfection.

\section{INTRODUÇÃO}

Solarização é um processo que utiliza a radiação solar para destruir compostos e/ou espécies indesejáveis presentes em um ambiente (NAVARRETE et al., 2004). Entretanto, muitos mecanismos bióticos e abióticos são potencializados, mediante solarização, no sentido da destruição e/ou inibição dos agentes patogênicos.
Radiação é um termo que se refere à emissão e propagação de energia eletromagnética na forma de ondas. A radiação solar constitui apenas uma parte de todo o espectro eletromagnético (ACRA et al., 1984). A energia gerada mediante a radiação solar penetra as superfícies ao atingí-las em função das propriedades térmicas do material constituinte, tais como, capacidade calorífica, condutividade e difusibilidade. (RIJAL; FUJIOKA, 2001).

${ }^{2}$ Universidade Estadual Paulista, Instituto de Geociências e Ciências Exatas, Departamento de Estatística, Matemática Aplicada e Computação, Rio Claro, Brasil. 
A radiação solar é composta de diferentes comprimentos de onda, cada qual com sua energia específica. A luz solar com comprimento de onda de $315-400$ $\mathrm{nm}$, compreendida na faixa do espectro da luz ultravioleta, é absorvida por compostos como os ácidos nucléicos. A radiação solar ao incidir sobre a matéria promove fotodegradação, induzindo ações mutagênicas e degenerações celulares (WEGELIN et al., 1994).

Somando-se os danos da energia radiante ao aquecimento decorrente da energizaçãoé possível decidirse a respeito dos níveis de letalidade dos patógenos em função do tempo (NAVArRete; ANGelis, 2003).

A solarização tem sido aplicada nas ciências agrárias para descontaminação do solo podendo eliminar muitas espécies de ervas daninhas (Amaranthus retroflexus, Digitaria sanguinalis e Galinsogaparviflora) dicotiledôneas, monocotiledôneas, fungos (Fusarium exosporium, Verticillum dahliae, Sclerotinia aryzae e Sclerotinia sp.), bactérias (Agrobacterium tumefaciens e Azotobacter spp.), vírus, artrópodes e nematóides (PINTO, 1992).

MARENGo; Lustosa (2000) verificaram a ação benéfica da solarização na eliminação de ervas daninhas no solo e o aumento na produtividade de cenoura (Daucus carotaL. vc. Brasília). Amaral et al. (2006) avaliaram a eficiência da radiação solar na desinfecção da água de poços rasos, e comprovaram que as maiores reduções ocorreram para Escherichia coli.

Com base nas informações acerca da eficiência da radiação solar na descontaminação do solo e desinfecção de água, procurou-se verificar a ação da radiação solar sobre a viabilidade de células em suspensão aquosa de Saccharomyces cerevisiae e Candida albicans, organismos eucariotos unicelulares.

S. cerevisiae é um microrganismo modelo de estudos nas diferentes áreas do conhecimento, inclusive nas interfaces das ciências biológica, química, física, biofísica e microbiologia; é utilizada na indústria da panificação e fermentação etanólica. $C$. albicansé uma levedura patogênica que se apresenta na forma unicelular ou na forma de pseudomicélio, com genoma cerca de $30 \%$ maior que o daS.cervisiae; é capaz de instalar-se no trato digestivo de $40-80 \%$ dos seres humanos e coexiste pacificamente com outros microrganismos. As infecções causadas por C. albicans constituem problemas de saúde conhecidos como candidíase ou "tordo". Os problemas de patologia surgem geralmente quando o indivíduo experimenta alterações na imunidade celular, na biota normal do corpo e/ou na fisiologia. A candidíase instala-se com freqüência na pele, mucosas e em organismos imunocomprometidos (Oliveira et al., 1998). Jarvis (1995), ao analisar 180 hospitais em um estudo epidemiológico, verificou que $72,1 \%$ das infecções fúngicas eram causadas por C. albicans.

Procurando conhecer mais a respeito de novas formas economicamente viáveis e sem agregação de insumos químicos para a desinfecção da água, com especial aplicação onde as condições sanitárias são precárias e a luminosidade natural é intensa, o presente trabalho teve como objetivos: verificar a eficácia da radiação solar na eliminação das leveduras $S$. cerevisiae e C. albicans de água de abastecimento públi$\mathrm{co}$, quando contaminada artificialmente e acondicionada em frascos de vidro e garrafas de politereftalato de etileno - PET - incolores e verdes e constatar a eficiência de cada material acondicionante no tempo de eliminação dessas células. Desta forma, o método proposto para eliminar S. cerevisiae e C. albicans baseia-se na morte celular decorrente da exposição temporária da suspensão celular à radiação solar.

\section{MATERIAL E MÉTODOS}

Células de Candida albicans provenientes de cultura estoque foram inoculadas em tubos de cultura contendo meio de extrato de levedura, peptona e dextrose (YEPD) (LOODER, 1971). A seguir foram incubadas em estufa a $28^{\circ} \mathrm{C}$ durante 48 horas. As células contidas nos tubos foram suspensas com o auxílio de solução salina constituindo-se as células do pré-inóculo. Da suspensão foram retiradas alíquotas que foram transferidas para Erlenmeyers contendo $150 \mathrm{~mL}$ de meio YEPD no estado líquido. Após 72 horas de agitação a cultura foi deixada em repouso (câmara fria) para decantação das células. Olíquido sobrenadante foi descartado. Células de $S$. cerevisiae foram obtidas diretamente no comércio na forma de fermento prensado Fleichmann Royal ${ }^{\circledR}$. As células foram suspensas em água destilada, a seguir decantadas e o sobrenadante descartado. As células remanescentes de $C$. albicans e $S$. cerevisiae foram utilizadas para contaminar a água. Após neutralização do cloro presente em água de abastecimento público por ação do tiossulfato de sódio, a água foi contaminada com as células das leveduras. Destas suspensões foram retiradas alíquotas de 1 $\mathrm{mL}$ sendo somado a cada uma delas $1 \mathrm{~mL}$ de eritrosina (SHARF, 1972) para contagem microscópica das células viáveis em câmara de Neubauer (tempo T0) contendo em média $45,0 \times 10^{5}$ células/mL. Em seguida, procedeu-se o preenchimento dos frascos de vidro e garrafas PET incolores e verdes com a água contaminada. Os frascos foram acomodados em bandejas revestidas com folhas de alumínio de modo a receberem máxima incidência luminosa. Frascos controle foram mantidos no escuro em câmara fria. Em intervalos de tempo foram retiradas alíquotas de cada 
frasco e a viabilidade celular quantificada em câmara de Neubauer.

\section{RESULTADOS}

Foram executados cinco experimentos com cada uma das leveduras a partir dos quais foram obtidos dois conjuntos de dados particulares referentes à quantificação da viabilidade celular das suspensões de S. cerevisiae e de C. albicans (Tabela 1). Calculada a média percentual dos eventos de falha (morte celular) para cada intervalo de tempo amostrado nos diferentes tipos de frascos acondicionantes das suspensões celulares, definiram-se as respectivas funções de sobrevivência para as suspensões celulares de $S$. cerevisiae e C.albicans, sendo estas apresentadas pelas Figuras1.1 e1.2. A probabilidade de um determinado número de células ser eliminado da água em um intervalo de tempo $\left(t_{1}-t_{2}\right)$ no processo de solarização pode ser expressa em termos da função de sobrevivência $S\left(t_{1}\right)-S\left(t_{2}\right)$. A taxa de falha (morte celular) no intervalo $\left(t_{1}-t_{2}\right)$ é definida como a probabilidade de que a morte celular ocorra neste intervalo, dado que esta não tenha ocorrido antes de $t_{1}$, dividida pelo comprimento do intervalo. As funções de taxa de falha para cada situação amostrada de solarização da água são apresentadas pelas Figuras 2.1 e 2.2 referentes à S. cerevisiae e C. albicans, respectivamente.

\section{DISCUSSÃO}

Os resultados evidenciam, ao analisar as funções de taxa de falha para cada microrganismo estudado em suas diferentes condições acondicionantes, que a taxa de morte celular aumenta com o transcorrer do tempo de solarização da água, pois tais funções são crescentes para todos os casos amostrados. Este comportamento mostra um efeito gradual de eliminação de $S$. cerevisiae e $C$. albicans da água contaminada. Verificou-se que a característica crescente mencionada para as taxas de morte celular é revelada em uma análise de tendência, porém, sabe-se que as referidas taxas de falha são, para a maioria das situações amostradas, uma combinação de curvas crescente e decrescente, principalmente nas primeiras horas de solarização da água. As interpretações do referido comportamento exigem estudos que foquem mais precisamente a célula e sua resposta temporal à radiação solar em uma análise que privilegie a ecologia populacional microbiana.

Como na análise de sobrevivência efetuada a variável resposta é o tempo até a ocorrência da eliminação total de formas vivas de células de $S$. cerevisiae e C. albicans, a leitura interpretativa das Figuras 1.1 e 1.2 revela diferente intervalo de tempo até a ocorrência do evento de interesse. A eficiência do vidro, como material acondicionante da suspensão celular de $S$. cerevisiae no tempo de desinfecção da água, reduziu em mais de $50 \%$ o tempo necessário para a eliminação total das referidas células se comparado ao tempo de eliminação transcorrido nas garrafas de politereftalato de etileno verdes. A explicação para tal eficiência aponta a necessidade de comparações efetivas da absorbância de cada material utilizado como acondicionante, além da resistência intrínseca de cada microrganismo que pode estar ligada ao genoma.

Tabela 1 - Quantificação da viabilidade celular de S. cerevisiae e C. albicans em câmara de Neubauer em função do tempo de exposição da suspensão celular à radiação solar (tempo noturno computado).

Número de células viáveis $\mathrm{mL}^{-1}$ por hora

\begin{tabular}{|c|c|c|c|c|c|c|c|}
\hline \multirow{2}{*}{$\begin{array}{l}\text { Material } \\
\text { acondicionante }\end{array}$} & \multicolumn{6}{|c|}{ Saccharomyces cerevisiae } & \multirow{2}{*}{$\begin{array}{l}\text { Controle* } \\
72 \\
\end{array}$} \\
\hline & 0 & 8 & 24 & 32 & 48 & 72 & \\
\hline Vidro & $61,2 \times 10^{5}$ & $11,3 \times 10^{5}$ & 0 & 0 & 0 & 0 & $56,6 \times 10^{5}$ \\
\hline PET incolores & $61,2 \times 10^{5}$ & $38,2 \times 10^{5}$ & $12,1 \times 10^{5}$ & 0 & 0 & 0 & $52,0 \times 10^{5}$ \\
\hline \multirow[t]{3}{*}{ PET verdes } & $61,2 \times 10^{5}$ & $48,9 \times 10^{5}$ & $32,8 \times 10^{5}$ & $13,3 \times 10^{5}$ & $8,5 \times 10^{5}$ & 0 & $51,6 \times 10^{5}$ \\
\hline & \multicolumn{6}{|c|}{ Candida albicans } & Controle* \\
\hline & 0 & 8 & 28 & 32 & 56 & 76 & 76 \\
\hline Vidro & $30,0 \times 10^{5}$ & $22,1 \times 10^{5}$ & $17,4 \times 10^{5}$ & $11,2 \times 10^{5}$ & $7,8 \times 10^{5}$ & 0 & $28,7 \times 10^{5}$ \\
\hline PET incolores & $30,0 \times 10^{5}$ & $23,7 \times 10^{5}$ & $18,3 \times 10^{5}$ & $12,5 \times 10^{5}$ & $8,4 \times 10^{5}$ & 0 & $27,5 \times 10^{5}$ \\
\hline PET verdes & $30,0 \times 10^{5}$ & $25,9 \times 10^{5}$ & $21,7 \times 10^{5}$ & $14,2 \times 10^{5}$ & $8,8 \times 10^{5}$ & 0 & $31,0 \times 10^{5}$ \\
\hline
\end{tabular}

*células de $S$. cerevisiae e C. albicans mantidas no escuro por 72 e 76 horas, respectivamente. 


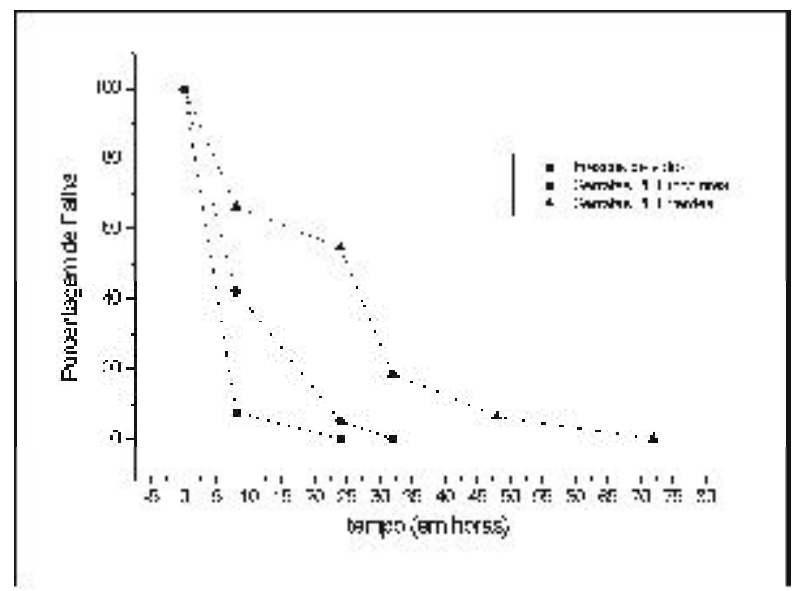

Fig. 1.1 - Funções de sobrevivência para suspensão celular de $S$. cerevisiae acondicionada em frascos de vidro e garrafas de politereftalato de etileno incolores e verdes expostas à irradiação solar direta.

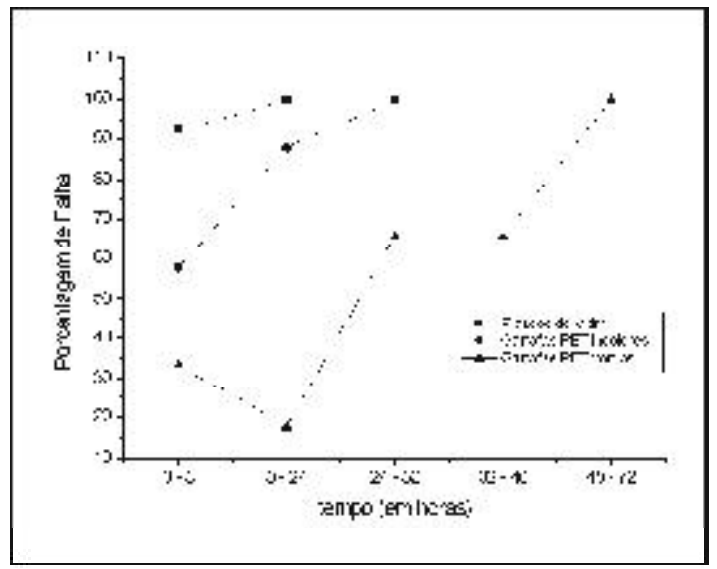

Fig. 2.1 - Funções de Taxa de Falha para suspensão celular de $S$. cerevisiae acondicionada em frascos de vidro e garrafas de politereftalato de etileno incolores e verdes expostas à solarização solar direta.

A interferência da absorbância específica dos materiais utilizados como constituintes dos recipientes para a água contaminada com C. albicans não possibilitou comparação de eficiência de reflectância entre os frascos, porém revelou resistência do microrganismo testado ao pontuar 76 horas como tempo transcorrido para sua eliminação total da água acondicionada sob os diferentes constituintes dos recipientes testados.

Outra variável a ser considerada é a turbidez da água que, segundoPfammatter; Wegelin (1993), deve apresentar um valor máximo de 30 NTU para uma boa eficiência da desinfecção solar.

A Portaria 518/2004 de 25 de março de 2004 do Ministério da Saúde estabelece procedimentos e responsabilidades relativos ao controle e vigilância da qualidade da água para consumo humano e seu padrão de potabilidade, porém não menciona aC.albicans como microrganismo patogênico com necessidade

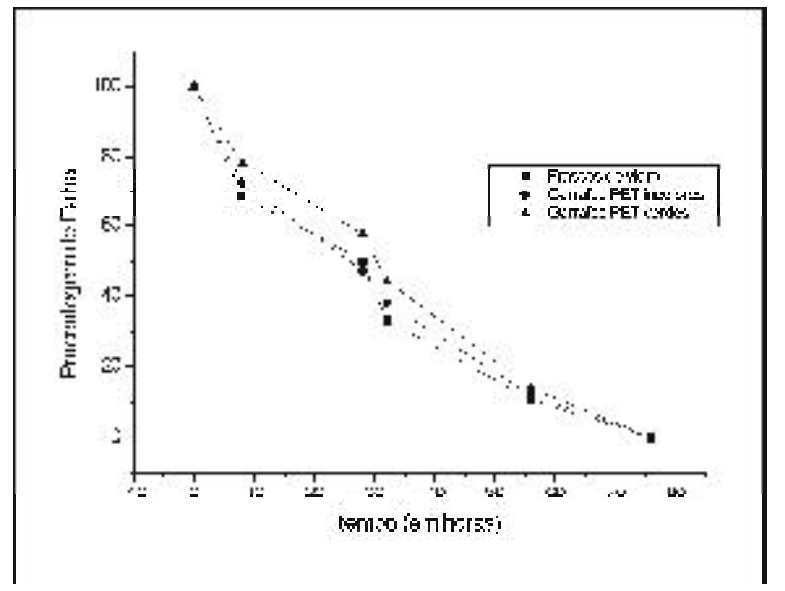

Fig. 1.2-Funções de sobrevivência para suspensão celular de C. albicans acondicionada em frascos de vidro e garrafas de politereftalato de etileno incolores e verdes expostas à irradiação solar direta.



Fig. 2.2 - Funções de Taxa de Falha para suspensão celular de C. albicans acondicionada em frascos de vidro e garrafas de politereftalato de etileno incolores e verdes expostas à solarização solar direta.

eventual de eliminação da água pelos processos de tratamento. Vale ressaltar o risco potencial deste patógeno à saúde pública, especialmente tratando-se decrianças as principais vítimas de candidíase. Além disso, a candidíase em muitos casos é de difícil tratamento (Gundmundur et al., 2001).

Pesquisas realizadas por ANGELIset al. (2003) e AMARAL et al. (2006) mostraram que é possível eliminar E. coli da água quando exposta à solarização. No caso da radiação solar sobre suspensão de bactérias, os autores demonstram que a exposição da água para consumo humano à radiação solar pode ser utilizada para diminuir o risco de enfermidades de veiculação hídrica.

Para o consumo humano da água solarizada, recomenda-se somar ao tempo de eliminação total de formas vivas dos levedos estudados, no mínimo, 8 horas de exposição à solarizaçãointensa. Em casos de interferência meteorológica sob a incidência plena 
dos raios solares, deve-se somar o tempo deinterferência ao tempo final de exposição para constatar a eficiência de desinfecção do método apresentado.

\section{CONCLUSÕES}

- Os resultados comprovaram a eficiência da solarização da água para a eliminação celular de $S$. cerevisiae e C. albicans presentes em suspensão aquosa mantida em frascos de vidro e garrafas de politereftalato de etileno incolores e verdes.

- A eficiência do vidro como material acondicionante da suspensão celular de S. cerevisiae reduziu em mais de $50 \%$ o tempo necessário para a eliminação total das referidas células se comparado ao tempo de eliminação dessas células nas garrafas de politereftalato de etileno verdes.

- Os resultados corroboraram aqueles obtidos por outros autores ao utilizar a solarização para a eliminação de outras espécies microbianas e demonstraram quea exposição da água, para consumo humano, à radiação solar pode ser utilizada para diminuir o risco de enfermidades de veiculação hídrica.

\section{AGRADECIMENTOS}

AoPrograma de AuxílioaoEstudantedaUNESP por intermédio da Bolsa PAE e ao Prof. Dr. Vitor José Mendes CardosodoInst. deBiociências(IB), DeptodeBotânica da Univ. Estadual Paulista(UNESP), Campus de Rio Claro.

\section{REFERÊNCIAS}

ACRA, A.; RAFFOUL, Z.; KARAHAGOPIAN, Y. Solar disinfection of drinking water and oral rehydration solutions. Paris: UNICEF, 1984.

AMARAL, L.A.; NUNES, A.P.; CASTANIA, J.; LORENZON, C.S.; BARROS, L.S.S.; NADER FILHO, A. Uso da radiação solar na desinfecção da água de poços rasos. Arquivos do Instituto Biológico, São Paulo, v.73, n.1, p.45-50, 2006.

ANGELIS, D.F.; SILVA, B.H.; PIRES, C.C.; BORGES, K.P. Diminuição da viabilidade de Escherichia coli pela luz solar utilizando garrafas "PET". In: CONGRESO DE INICIAÇÃO CIENTÍFICA DA UNESP, 15., 2003, Marília, SP. Resumos. Marília: 2003. 1CD-ROM.

AYRES, M.; AYRES JUNIOR, L.; AYRES, D.L.; SANTOS, A.S. Bioestat 2.0: aplicações estatísticas nas áreas das ciências biológicas e médicas. Belém: Sociedade Civil Mamirauá; Brasília: CNPq, 2000.

GUNDMUNDUR B.; GUDMUNDUR, B.; ARFINNSSON, J.; STEINGRÍMSSON, O.; THORMAR, H. In vitro Killing of Candida albicans by fatty acids and monoglycerides. Antimicrobial Agents and Chemoterapy; v.45, n.11, p.32093212, 2001

JARVIS, RW. Epidemiology of nasocamial fungal infections, with emphasis in Candida albicans species. Clinical Infections Diseases, v.20, p. 1526-1530, 1995.

LOODER J. The yeasts. A taxonomic study. 2.ed. Amsterdam: North Holland Publishing Company, 1971. 1385p.

MARENCO, R.A.; LUSTOSA, D.C. Solarização do solo para o controle de plantas daninhas na cultura de cenoura. Pesquisa Agropecuária Brasileira, v.35, n.10, p.2025-2032, 2000.

NAVARRETE, A.A.; ANGELIS, D.F. Efeito da Solarização sobre a viabilidade celular de Saccharomyces cerevisiae. In: CONGRESO DE INICIAÇÃO CIENTÍFICA DA UNESP, 15., 2003, Marília, SP. Resumo. Marília: 2003. Resumo 083. 1CD-ROM.

NAVARRETE, A.A.; ANGELIS, D.F.; COSTA, M. R. Eliminação de Candida albicans da água mediante a solarização. In: CONGRESSO DE INICIAÇÃO CIENTÍFICA EM CIÊNCIAS AGRÁRIAS, BIOLÓGICAS E AMBIENTAIS, 2., São Paulo, SP. Resumo. São Paulo: Instituto Biológico, 2004. Resumo 064. 1-CD-ROM.

OLIVEIRA, E.E.; SILVA, S.C.; SOARES, A.J.; ATTUX, C.; CRUVINEL, B.; RODRIGUES SILVA, M.R. Toxinas Killer e produção de enzimas por Candida albicans isoladas da mucosa bucal de pacientes com câncer. Revista da Sociedade Brasileira de Medicina Tropical, v.31, n.6, p.523-527, 1998.

PINTO A. Solarização do solo em estufa. 1992. Dissertação (Mestrado em Proteção Integrada) - Instituto Superior de Agronomia, Universidade Técnica de Lisboa, Lisboa, 1992.

PFAMMATTER, R.; WEGELIN, M. Solar water disinfection: evaluation of field tests carrie out in Cali, Colombia. Cali: Internal Monitoring Report, 1993.

RIJAL, G.K.; FUJIOKA, R.S. Synergistic effect of solar radiation and solar heating to disinfect drinking water sources. Water Science and Technology, v.43, n.12, p.155162, 2001.

SHARF J.M. Exame microbiológico de alimentos. 2.ed. São Paulo: Poligono, 1972. 257p.

WEGELIN, M; CANONICA, S; MECHSNER, K; FLEISCHMANN, T; PESARO, F; METZLER, A. Solar water disinfection: scope of the process and analysis of radiation experiments. AQUA, London, v.43, n.4, p.154-169, 1994.

Recebido em 2/5/06

Aceito em 10/3/08 